\title{
The NAO signal in daily rainfall series over the Iberian Peninsula
}

\author{
M. C. Gallego ${ }^{1, *}$, J. A. García ${ }^{1}$, J. M. Vaquero ${ }^{2}$ \\ ${ }^{1}$ Departamento de Física, Facultad de Ciencias, Universidad de Extremadura, Avda. de Elvas, s/n, 06071 Badajoz, Spain \\ ${ }^{2}$ Departamento de Física, Escuela Politécnica, Universidad de Extremadura, Avda. de la Universidad, s/n, 10071 Cáceres, Spain
}

\begin{abstract}
The North Atlantic Oscillation (NAO) is the principal mode of climatic variability over the North Atlantic, playing an important role in the climate of the Iberian Peninsula. Generally, investigations into the effect of the NAO over this area have been performed using data at a monthly scale. Here, we conducted a more detailed study using series of the daily rainfall over Iberia, defining several indices related to the frequency and intensity of the rainfall in this area. The objective was to search for possible relationships between these daily rainfall indices, which hold information that cannot be reproduced using monthly rainfall series, and the NAO index. The winter NAO index (wNAO) was found to have clear negative correlations with high values of both the frequency and the intensity of winter rainfall over certain regions of the peninsula, and with the winter rainfall maxima, and a positive correlation with winter dry spell maxima. The regions showing the strongest correlations were the west, southwest, and interior of the peninsula. While the wNAO was found to affect essentially the category of intense rainfall in this area, both in frequency and in accumulated values, other rainfall categories (especially light and moderate rainfall) were less affected by changes in the wNAO. In sum, the association between the wNAO and the winter total rainfall indices, in number of cases and in accumulated values, is primarily due to the effect that wNAO has on intense winter rainfall events.
\end{abstract}

KEY WORDS: Daily rainfall $\cdot$ Iberian Peninsula $\cdot$ NAO index

\section{INTRODUCTION}

The North Atlantic Oscillation (NAO) is the most significant driver of winter climatic variability over the North Atlantic region, and one of the most broadly studied climatic indices in the literature (Hurrell et al. 2003). According to Linés (1981), much of the rainfall in the Iberian Peninsula is due to frontal systems coming from the North Atlantic. One therefore expects a relationship to exist between the rainfall series measured over the Iberian Peninsula and the NAO. Indeed, such teleconnections between the North Atlantic and large-scale weather over Europe have been demonstrated by, e.g., Ratcliffe \& Murray (1970), Meehl \& van Loon (1979), Barnett (1984), García et al. (2001), and Trigo et al. (2002). With respect to the Iber- ian Peninsula, the influence of the NAO on the peninsula's rainfall has been shown by several workers, including Zorita et al. (1992), Rodríguez-Puebla et al. (1998), García et al. (2002), Goodess \& Jones (2002), Mateos et al. (2002), Muñoz-Díaz \& Rodrigo (2003), and Trigo et al. (2004). However, these studies used monthly rainfall series, so that the only characteristic of rainfall studied was the accumulated quantity in each month. In the present work, we take the study of this NAO-Peninsula rainfall relationship a little further, by using a temporal scale that reflects the structure of the rainfall: the daily time-scale more clearly. Due to the episodic character of rainfall, an exhaustive study needs to analyze both the frequency of occurrence and the intensity of the events. At the daily scale in particular, the structure of the rainfall is related to the 
sequence of dry days and wet days and the value of the daily accumulated rainfall. The importance of studying these different characteristics of rainfall-frequency, intensity, and duration of events - in the context of a changing climate has been noted by Trenberth et al. (2003), among others. There are various statistical models in the scientific literature that take these characteristics of precipitation into account in studying rainfall processes. These include Markov chains, recurrence theory, Poisson processes, and NeymanScott cluster models (see Waymire \& Gupta 1981 for more information). Their results, however, are sometimes difficult to interpret because of the complexity of the dual analysis of both the frequency and the intensity of precipitation. In the present study, therefore, instead of applying one of these statistical models directly to the daily rainfall series, we use a technique now recommended and directed by CLIVAR through the Expert Team on Climate Change Detection, Monitoring and Indices (ETCCDMI, www.clivar.org/organization/etccd/): the creation of rainfall indices as indicators of climate variability. These series of daily rainfall indices simplify the analysis of the structure of the rainfall on a daily time-scale. In particular, using the daily rainfall data series, we constructed series of rainfall indices based on the frequency and intensity of the rainfall events by defining different categories of rainfall exceeding certain thresholds. As frequency indices we took the number of rainy days and dry spells in each category, and as intensity indices the values of accumulated rainfall in each category and the rainfall maxima. Because of the high degree of seasonality of rainfall in the Iberian Peninsula, each index was evaluated separately for each season as follows: spring (March-April-May), summer (June-JulyAugust), autumn (September-October-November), and winter (December-January-February).

For each observatory and season, we applied a rank-based Kendall test as a measure of the correlation between the NAO index series and each of the series of indices. This non-parametric test was selected due to the non-normality of the daily rainfall events in Iberia. The resulting Kendall statistic $r_{k}$ and its significance level was also subjected to a spatial study.

Thus, the main aims of the present work were: (1) to study which daily rainfall indices in Iberia are influenced by the NAO index; (2) to identify spatially coherent regions with a common influence of the NAO.

The structure of the paper is as follows: Section 2 describes the data used for the study and the construction of the rainfall index series. The relationships found between the NAO index and the rainfall index series are discussed in Section 3. The pertinent conclusions are presented in Section 4.

\section{DATA}

The data used in this study were daily rainfall series at 35 observatories distributed over the Iberian Peninsula during the period 1958 to 1997 . They were kindly supplied by 3 sources: Instituto Nacional de Meteorología de España (INM, www.inm.es), European Climate Assessment and Dataset (ECA, http://eca.knmi. $\mathrm{nl}$ ), and Real Instituto y Observatorio de la Armada Española en San Fernando (Cádiz) (ROA, www.roa. es). A selection was made from a larger set of data series, taking into account their temporal extension with as few gaps as possible (in all cases $<2 \%$ ), and their spatial location in order for the sample to be representative of the orographic diversity of the Iberian Peninsula. The data were first represented graphically for a preliminary verification of the goodness of their behaviour. A further check of the homogeneity of the series by means of Buishand tests (Buishand 1982) showed all the series to be homogeneous.

As noted above, the daily rainfall series were broken down into frequency and intensity in order to extract information on rainfall structure. It was therefore necessary to distinguish different types of rainfall by defining specific thresholds representative of each type.

There is no uniformly accepted criterion in the literature for the definition of such thresholds. Some authors take fixed thresholds to study their rainfall series, based on a specific value of the rainfall that depends on the pluviometric status of the region under study (e.g. Karl \& Knight 1998, Brázdil et al. 1999, Kunkel et al. 1999, Brunetti et al. 2002, and GarcíaHerrera et al. 2003). Others opt for the use of spatially variable thresholds based on certain percentiles of rainfall, but these are usually applied to the study of intense rain, using the higher percentiles (Suppiah \& Hennessy 1998, Nicholls \& Murray 1999).

In our case, the choice of the most appropriate criterion was somewhat complicated. The orographic diversity of the peninsula and local phenomena cause the intensities to vary sharply from one observatory to another. A choice of fixed thresholds does not seem therefore to be very suitable for establishing the different categories of the peninsula's rainfall. While spatially variable thresholds seem preferable, any given category would then include very dissimilar rainfall values from different regions. The criterion finally adopted aimed at a compromise between the 2 definitions, taking as fixed thresholds the average over all the observatories of the values of certain percentiles of seasonal rainfall. In particular, the $33 \%$ percentile was taken as the light/moderate boundary, and the $66 \%$ percentile as the moderate/intense boundary. The observed mean values for these percentiles were $2.5 \mathrm{~mm}$ and $7.5 \mathrm{~mm}$, 
Table 1. Indices of rainfall frequency and intensity. PRCP: precipitation

\begin{tabular}{|lll|}
\hline & Category & Description \\
\hline $\begin{array}{l}\text { Rainfall frequency } \\
\text { Number of rainy days }\end{array}$ & Total & Seasonal count of days when PRCP $\geq 0.1 \mathrm{~mm}$ \\
& Light & Seasonal count of days when $0.1 \mathrm{~mm} \leq \mathrm{PRCP}<2.5 \mathrm{~mm}$ \\
& Soderate & Seasonal count of days when $2.5 \mathrm{~mm} \leq \mathrm{PRCP}<7.5 \mathrm{~mm}$ \\
& Seasonal count of days when PRCP $\geq 7.5 \mathrm{~mm}$ \\
& Very intense & Seasonal count of days when PRCP $\geq 15 \mathrm{~mm}$ \\
Dry spells & Medians & Seasonal median of no. of consecutive days with PRCP $<0.1 \mathrm{~mm}$ \\
& Maxima & Seasonal maximum of no. of consecutive days with PRCP $<0.1 \mathrm{~mm}$ \\
& & \\
Rainfall intensity & Total & Seasonal rainfall amount when PRCP $\geq 0.1 \mathrm{~mm}$ \\
Accumulated rainfall & Sight & Seasonal rainfall amount when $0.1 \mathrm{~mm} \leq \mathrm{PRCP}<2.5 \mathrm{~mm}$ \\
& Moderate & Seasonal rainfall amount when $2.5 \mathrm{~mm} \leq \mathrm{PRCP}<7.5 \mathrm{~mm}$ \\
& Seasonal rainfall amount when PRCP $\geq 7.5 \mathrm{~mm}$ \\
Rainfall maxima & Very intense & Seasonal rainfall amount when PRCP $\geq 15 \mathrm{~mm}$ \\
& & Seasonal maximum 1-day precipitation \\
\hline
\end{tabular}

respectively (daily values). In addition to the light, moderate, and intense rainfall events, a further category, very intense precipitation events, was considered because of their importance due to the damage that they can cause. The very intense rainfall boundary was taken to be the $90 \%$ percentile. The corresponding observed mean value was approximately $15 \mathrm{~mm}$. Haylock \& Nicholls (2000) took a similar approach in a study of rainfall in Australia because of the great spatial variability of rainfall intensity over that continent. Hence, with the same thresholds for all the stations, we established 4 categories of rainfall in the peninsula: light $(0.1-2.5 \mathrm{~mm})$, moderate $(2.5-7.5 \mathrm{~mm})$, intense $(>7.5 \mathrm{~mm})$, and very intense $(>15 \mathrm{~mm})$. These, together with the total rainfall $(>0.1 \mathrm{~mm})$, constitute the set of categories for which the rainfall indices are evaluated. They are consistent with those used in the ECA project (http://eca.knmi.nl/documents/Appendix_E.pdf), but adapted to the values of rainfall in Iberia.

Seasonal series of rainfall indices were constructed from the daily rainfall series for each of the 35 observatories. One set of series, related to the frequency of rainfall, consisted of the number of rainy days in the categories of total, light, moderate, intense, and very intense rainfall, for each season of the year. Also related to the frequency, and complementary to the previous set, were the series of medians and maxima of dry spells counting the number of dry days between 2 total rain events. Series related to rainfall intensity were constructed based on the accumulated rainfall in each category during each season. The maxima of seasonal rainfall were also studied. These indices are included in the definitions of the 27 ETCCDMI core indices (http://cccma.seos.uvic.ca/ETCCDMI/ index.shtml). The description of this set of indices is summarized in Table 1 for frequency and intensity, respectively. Further information about the spatial distribution of the frequency indices over Iberia may be found in Gallego et al. (2004). These series of indices reflect the structure of the peninsula's rainfall, and may allow one to determine any relationship that exists between the NAO and the different categories of rainfall over the Iberian Peninsula. In order to check for the possibility of an increasing number of low precipitation events due to improvements in rain gauges, the light and total categories were re-computed taking $1 \mathrm{~mm}$ as the rainfall minimum. No significant differences were found in the results between the 2 minimum rainfall values.

\section{RELATIONSHIP BETWEEN THE NAO INDEX AND THE SERIES OF RAINFALL INDICES}

The NAO is one of the most prominent and recurrent patterns of atmospheric circulation variability, and dictates the climatic variability of a great part of the Northern Hemisphere (Hurrell et al. 2003). In the region of study of the present work, it is known that the index with both the most intense signal and the greatest influence on the Iberian Peninsula is the winter NAO index (wNAO). To determine which characteristics and categories of the daily rainfall over Iberia are influenced by the NAO index, 2-sided rank-based Kendall tests as measures of the correlation were performed between each series of rainfall indices and the NAO index series. The null hypothesis of the Kendall test was the non-existence of any association 1 between

\footnotetext{
${ }^{1}$ We use the term association to mean a statistically significant correlation obtained by means of the rank-based Kendall test as a measure of the correlation between 2 variables
} 
the NAO and the respective rainfall index, and the alternative hypothesis was the existence of such an association, independently of whether it be positive or negative. The sign of the association was taken to be the sign of the Kendall statistic, $r_{k}$. The evaluation of the test was made for 2 significance levels: $10 \%$ and $5 \%$. The NAO series used were those constructed by Hurrell 1995 (www.cgd.ucar.edu/cas/jhurrell/indices. $\mathrm{html}$ ). These series and the rainfall index series are seasonal. The period of study chosen was 1958 to 1997. Since we believed the wNAO to be the strongest over our region, we performed preliminary correlations between the wNAO and the rainfall indices in each season by means of the Kendall test. The most significant values of $r_{k}(\sim \pm 0.6)$ were obtained with the winter data. The other seasons-spring, summer, and autumn - gave lower and very isolated significant values of $r_{k}(\sim \pm 0.2)$. Season-to-season calculations, correlating the NAO index in each season with the series of rainfall indices in the same season, gave practically the same results, and only in winter was a significant association found. Henceforth, therefore, we shall only present the results for that season.

The number of associations found in winter for the period 1958 to 1997 is summarized in Table 2. Many of the observatories present a negative association in the Kendall test for the series of number of rainy days, accumulated rainfall, and rainfall maxima, whereas dry spells present a positive association with the wNAO. This is consistent with the findings of MuñozDíaz \& Rodrigo (2003) and Yiou \& Nogaj (2004) that, in southern Europe, rainfall extremes are controlled by NAO- (floods) and NAO+ (droughts). Only for the category of light rainfall, both in number of cases and in accumulated rainfall, does there exist a mixture of negative and positive associations.

With respect to the number of cases, the greatest number of associations observed (all negative) corresponds to the total and intense categories of winter rainfall. With respect to the accumulated rainfall also, the total and intense rainfall categories present the greatest number of negative associations with wNAO. For both the frequency and intensity characteristics, the categories that follow in the number of associations found are those of moderate and very intense rainfall (with the same number) and, finally, light rainfall. This suggests that the association between wNAO and the total rainfall indices, both in the number of rainy days and in the accumulated values, is mainly through the influence of the wNAO on the intense rainfall rather than on light rainfall. This hypothesis is further supported by the values of the $r_{k}$ statistic given by the Kendall test. Figs. 1 to 6 show maps of these values for various daily rainfall indices at all of the observatories, constructed by interpolation over the Iberian
Table 2. Number of associations found between the wNAO series and each of the winter series of rainfall indices. WA: without association

\begin{tabular}{|lccc|}
\hline & - & + & WA \\
\hline Number of rainy days & & & \\
Total rainfall & 29 & 0 & 6 \\
Light rainfall & 12 & 1 & 22 \\
Moderate rainfall & 25 & 0 & 10 \\
Intense rainfall & 29 & 0 & 6 \\
Very intense rainfall & 25 & 0 & 10 \\
Dry spells & & & \\
Medians & 0 & 18 & 17 \\
Maxima & 0 & 27 & 8 \\
Accumulated rainfall & & & \\
Total rainfall & 29 & 0 & 6 \\
Light rainfall & 17 & 1 & 17 \\
Moderate rainfall & 24 & 0 & 11 \\
Intense rainfall & 29 & 0 & 6 \\
Very intense rainfall & 24 & 0 & 11 \\
Rainfall maxima & 17 & 0 & 18 \\
\hline
\end{tabular}

Peninsula in order to check for the existence of coherent regions having a similar association with wNAO. For the total rainfall category in winter, Figs. 1 \& 2 show the existence of a strong association between the wNAO and the number of rainy days and the accumulated values, respectively. The greatest values (in absolute terms) of this association correspond to a large area which includes the west, southwest, and interior of the Iberian Peninsula, and are found for the category of intense winter rainfall both in number of cases and in the accumulated values, as shown in Figs. $3 \& 4$.

The behaviour of the maxima of the dry spells is opposite to that of the total number of rainy days, there being a positive correlation with wNAO over an extensive region of the peninsula (Fig. 5). The medians of the dry spells do not seem to be affected by NAO as much as other indices. They have a positive association for about half of the observatories, but without any spatial coherence. This may be due to the robustness of this index as an estimator, so that one would expect it to be less affected by external agents. The rainfall maxima, although with lower values of the statistic, show negative associations in the region of the greatest wNAO influence (Fig. 6), and there is also a negative association between wNAO and accumulated rainfall. In agreement with the findings of monthly data analyses, the smallest associations correspond to observatories near the Mediterranean and Cantabrian Seas. For the rest of the rainfall indices, the values of the correlation are smaller, and local patterns of behaviour appear that give rise to isolated regions in the maps that are very difficult to interpret. 


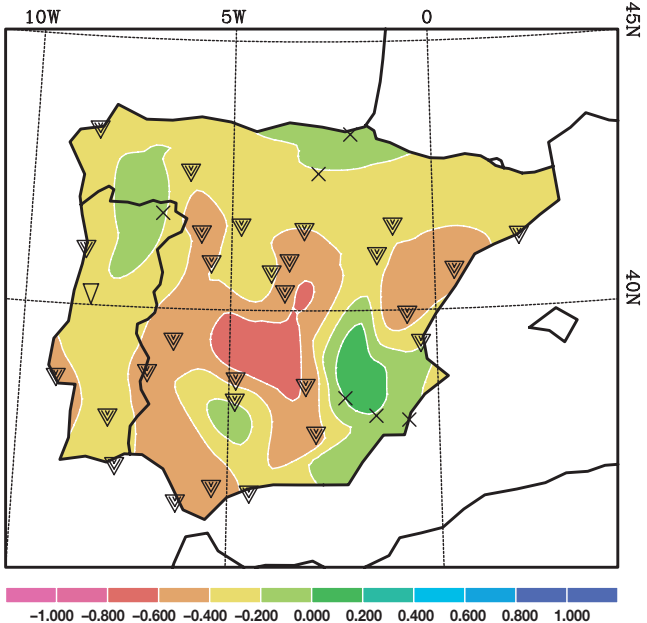

Fig. 1. Kendall test of the association: winter NAO index (wNAO) - total number of rainy days in winter. Symbols explained below

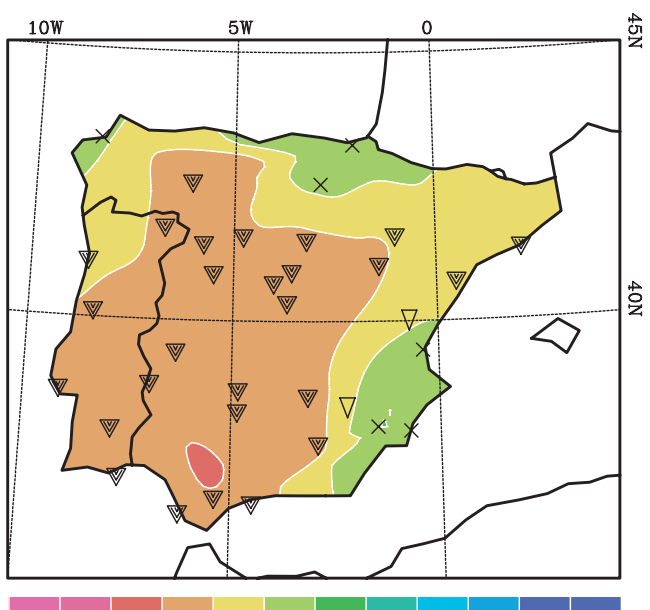

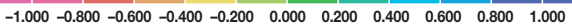

Fig. 2. Kendall test of the association: wNAO - total accumulated rainfall in winter. Symbols explained below

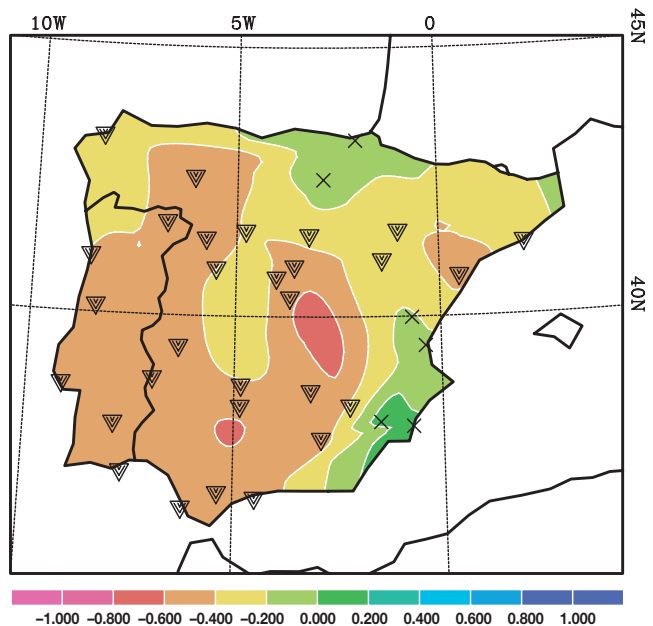

Fig. 3. Kendall test of the association: wNAO-number of intense rainy days in winter. Symbols explained below

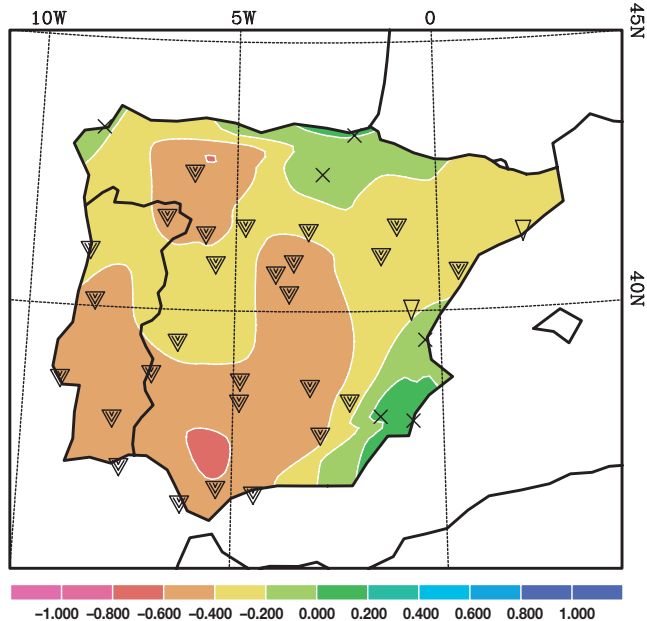

Fig. 4. Kendall test of the association: wNAO - accumulated intense rainfall in winter. Symbols explained below



Fig. 5. Kendall test of the association: wNAO - maxima of dry spells in winter. Symbols explained below

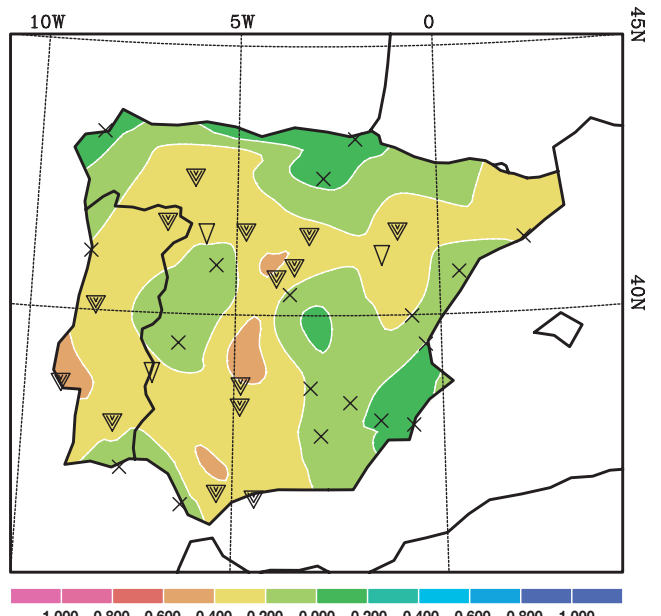

Fig. 6. Kendall test of the association: wNAO-maxima of rainfall in winter. Symbols explained below

Legend to figures: Isolines show the value of the Kendall statistic $r_{k}$. Symbols show the significance level for each observatory: $5 \%$ (filled triangles) and 10\% (hollow triangles). The orientation of the triangles indicates the positive (up) or negative (down) character of the associations found, and crosses indicate no association 
It is known that a negative association exists between wNAO and the monthly accumulated rainfall which is especially marked in the west and southwest of the Iberian Peninsula. As can be seen in Figs. 1 to 4, this negative association carries over to other indices of daily rainfall. Similar zones emerged for the rainfall indices that presented the greatest associations with the wNAO: the west and southwest of the Iberian Peninsula together with the interior as the best correlated regions, with a negative association to the wNAO index; the Mediterranean coast and the north of Iberia as the worst correlated regions, almost without association to wNAO; and the rest of the Iberian peninsula, with less marked behaviour. This distribution of the correlation is coherent with the correlations reported by other workers, such as Goodess \& Jones (2002), at the monthly and seasonal scales for rainfall amounts over Iberia, and the small associations found close to the Mediterranean Sea and the north of Iberia are in agreement with conclusions drawn from the monthly data (Hurrell 1995, Rodó et al. 1997, Esteban-Parra et al. 1998).

\section{SUMMARY AND CONCLUSIONS}

The influence of the NAO on monthly precipitation over Iberia has been well documented. In the present study, we went one stage further by analyzing this influence on the daily rainfall over this area, taking into account the characteristics of the precipitation represented by frequency and intensity. In particular, defining frequency and intensity rainfall indices for different rainfall categories, we explored which characteristics and categories of daily rainfall over Iberia are influenced by the NAO index, and identified spatially coherent regions with a common influence of the NAO.

The results confirmed that the wNAO is negatively well-correlated with rainy spells corresponding to large amounts of rainfall, in both frequency and intensity, over the west, southwest, and interior of the Iberian Peninsula. It is also significantly negatively correlated with the winter rainfall maxima, and positively well-correlated with the winter maxima dry spells. From these results, one could say that the wNAO essentially affects the category of intense rainfall, both in frequency and in accumulated values, and that other categories of rainfall (especially light and moderate) are less affected by changes in wNAO. Hence, the association between the wNAO and the winter total rainfall indices, in number of cases and in accumulated values, is primarily due to the effect that wNAO has on intense winter rainfall.

The reason may be that a NAO negative phase has a weak subtropical high pressure centre, with the storm track at lower latitudes than usual. This allows cyclonic perturbations and associated frontal systems to pass across the Iberian Peninsula. They bring moistureenriched air (Hurrell 1995) that drives intense precipitation especially over the west, southwest, and interior of Iberia, the regions most affected by these frontal systems coming from the North Atlantic Ocean (Linés 1981). A NAO positive phase would drive these frontal systems to higher latitudes and their effects over Iberia would be restricted to the northwest. Precipitation over the Mediterranean coast is due less to the effect of these frontal systems than to the mesoscale system associated with more local convective phenomena, hence its weak association with NAO.

These features would explain why the spatial distribution of the Kendall statistic $r_{k}$ evaluated for each winter rainfall index - wNAO pair of series showed the west, southwest, and interior of the Iberian Peninsula to be the regions best correlated with the wNAO, and the Mediterranean coast and north of Iberia to be the worst correlated zones. These results are consistent with those obtained by other workers using monthly data, and indicate that the marked changes observed at the monthly scale are related to changes in the frequency of the intense categories of daily precipitation. Our current research efforts focus on identifying the more detailed physical mechanisms that underlie the present findings, in part following the lines set out by Corte-Real et al. (1999), Ulbrich et al. (1999) and Goodess \& Jones (2002) for the monthly scale data.

Acknowledgements. This work was partially supported by C.I.C.Y.T. funds through the project CLI99-0845-C03-03 and by M.C.Y.T. funds through the project REN2002-04558-C0403 . The authors would like to thank the Instituto Nacional de Meteorología de España, European Climate Assessment and Dataset (ECA), and the Real Instituto y Observatorio de la Armada Española en San Fernando for providing the precipitation data for this study.

\section{LITERATURE CITED}

Barnett TP (1984) Statistical prediction of seasonal air temperature over Eurasia. Tellus 36A:132-146

Brázdil HR, Forland R, Tuomenvirta $\mathrm{H}$, Alexandersson $\mathrm{H}$ and 6 others (1999) Progress in the study of climate extremes in northern and central Europe. Clim Change 42:151-181

Brunetti M, Maugeri M, Nanni T, Navarra A (2002) Droughts and extreme events in regional daily Italian precipitation series. Int J Climatol 22:543-558

Buishand TA (1982) Some methods for testing the homogeneity of rainfall records. J Hydrol 58:11-27

Corte-Real J, Qian B, Xu H (1999) Circulations patterns, daily precipitation in Portugal and implications for climate change simulated by the second Hadley Center GCM. Clim Dyn 15:921-935

Esteban-Parra MJ, Rodrigo FS, Castro-Díez Y (1998) Spatial 
and temporal patterns of precipitation in Spain for the period 1880-1992. Int J Climatol 18:1557-1574

Gallego MC, García JA, Vaquero JM (2004) Distribución espacial de índices de frequencia de precipitación diaria en la Península Ibérica. Física Tierra 16:161-174

García R, Gallego D, Hernández E, Gimeno L, Ribera P (2001) Influence of the North Atlantic Oscillation on the Canary Islands precipitations. J Clim 14:3889-3903

García JA, Serrano A, Gallego MC (2002) A spectral analysis of Iberian monthly rainfall. Theor Appl Climatol 71:77-95

García-Herrera R, Gallego D, Hernández E, Gimeno L, Ribera P, Calvo N (2003) Precipitation trends in the Canary Islands. Int J Climatol 23:235-241

Goodess CM, Jones PD (2002) Links between circulation and changes in the characteristics of Iberian rainfall. Int $\mathrm{J}$ Climatol 22:1593-1615

Haylock M, Nicholls N (2000) Trends in extreme rainfall indices for an updated high quality data set for Australia, 1910-1998. Int J Climatol 20:1533-1541

Hurrell JW (1995) Decadal trends in the North Atlantic Oscillation: regional temperatures and precipitation. Science 269:676-679

Hurrell JW, Kushnir Y, Ottersen G, Visbeck M (eds) (2003) The North Atlantic Oscillation: climatic significance and environmental impact. Geophysical Monograph Series, Vol 134, American Geophysical Union, Washington, DC

Karl TR, Knight RW (1998) Secular trends of precipitation, frequency and intensity in the United States. Bull Am Meteorol Soc 79:231-241

Kunkel KE, Andsager K, Easterling R (1999) Long-term trends in extreme precipitation events over conterminous United States and Canada. J Clim 12:2515-2527

Linés A (1981) Perturbaciones típicas que afectan a la Península Ibérica y precipitaciones asociadas. Instituto Nacional de Meteorología, Madrid

Mateos VL, García JA, Serrano A, Gallego MC (2002) Transfer function modeling of the monthly accumulated rainfall series over the Iberian Peninsula. Atmosfera 15:237-256

Meehl GA, van Loon H (1979) The seesaw in winter temperatures between Greenland and northern Europe. Part III: Teleconnections with lower latitudes. Mon Weather Rev 107:1095-1106

Muñoz-Díaz D, Rodrigo FS (2003) Effects of the North Atlantic Oscillation on the probability for climatic categories of local monthly rainfall in southern Spain. Int J Climatol 23:

Editorial responsibility: Otto Kinne,

Oldendorf/Luhe, Germany
381-397

Nicholls N, Murray W (1999) Workshop on indices and indicators for climate extremes: Asheville, NC, USA, 3-6 June (1997) Breakout Group B: Precipitation. Clim Change 42: 23-29

Ratclife RAS, Murray R (1970) New lag associations between North Atlantic sea temperature and European pressure applied to long-range weather forecasting. Q J R Meteorol Soc 96:226-246

Rodó X, Baert E, Comin FA (1997) Variations in seasonal rainfall in Southern Europe during the present century: relationships with the North Atlantic Oscillation and the El Niño-Southern Oscillation. Clim Dyn 13:275-284

Rodríguez-Puebla C, Encinas AH, Nieto S, Garmendia J (1998) Spatial and temporal patterns of annual precipitation variability over the Iberian Peninsula. Int J Climatol 18:299-316

Suppiah R, Hennessy KJ (1998) Trends in total rainfall, heavy rain events and the number of dry days in Australia, 1910-1990. Int J Climatol 18:1141-1164

Trenberth KE, Dai A, Rasmussen RM, Parsons DB (2003) The changing character of precipitation. Bull Am Meteorol Soc 84(9):1205-1217

Trigo RM, Osborn TJ, Corte-Real J (2002) The North Atlantic Oscillation influence on Europe: climate impacts and associated physical mechanisms. Clim Res 20:9-17

Trigo RM, Pozo-Vázquez D, Osborn TJ, Castro-Díez Y, Gámiz-Fortis S, Esteban-Parra MJ (2004) North Atlantic Oscillation influence on precipitation, river flow and water resources in the Iberian Peninsula. Int J Climatol 24: 925-944

Ulbrich U, Christoph M, Pinto JG, Corte-Real J (1999) Dependence of winter precipitation over Portugal on NAO and baroclinic wave activity. Int J Climatol 19:379-390

Waymire E, Gupta VK (1981) The mathematical structure of rainfall representations. I. A review of the stochastic rainfall models. Water Resour Res 17(5):1261-1272

Yiou P, Nogaj M (2004) Extreme climatic events and weather regimes over the North Atlantic: when and where? Geophys Res Lett 31:L07202, doi:101029/(2003) GL019119

Zorita E, Kharin V, von Storch H (1992) The atmospheric circulation and sea surface temperature in the North Atlantic area in winter: their interaction and relevance for Iberian precipitation. J Clim 5:1097-1108

Submitted: March 3, 2005; Accepted: June 22, 2005

Proofs received from author(s): August 1, 2005 